\title{
PERSONAL HYGIENE AND THE RISK OF LEPROSY: A META-ANALYSIS FROM CASE CONTROL STUDY
}

\author{
Priscilla Jessica Pihaheyi,2), Bhisma Murti²), Yulia Lanti Retno Dewi3) \\ 1)Health Polytechnics Ministry of Health, Sorong, Papua Barat \\ 2)Masters Program in Public Health, Universitas Sebelas Maret \\ 3)Faculty of Medicine, Universitas Sebelas Maret
}

\begin{abstract}
Background: Leprosy is caused by Mycobacterium leprae (M. leprae) which is transmitted through nasal and oral fluids. The incubation period for M. leprae ranging from 3 years to 20 years. The impact of leprosy is a disability that reduces the quality of life. Social contact to patients can increase the risk of leprosy. This study aimed to determine the relationship between personal hygienic and the risk of leprosy.

Subjects and Method: This was a meta-analysis and systematic review on the Leprosy determinants. This study was conducted by search published articles from PubMed, ProQuest, Science Direct, Scopus, Spinger Link, EBSCO, Google Scholar, Embase, LILACS, Embase, Emerald, PLOS, and Indonesian National Library (Perpusnas) electronic databases. "leprosy OR hansen desease AND risk factor AND Personal hygiene OR sanitation AND odds ratio" keywords were inserted to find related articles. The inclusion criteria were full text, open access article, published from 1949 to 2020, using Indonesian or English language, case control study, and reporting adjusted odds ratio (aOR). The articles were analyzed using PRISMA flow chart and Revman 5.3.

Results: 4 articles were met the criteria. A sample of 297 cases and 297 controls was selected for this study. This study reported that poor personal hygiene increased the risk of Leprosy 3.52 times $(\mathrm{aOR}=3.52 ; 95 \% \mathrm{CI}=2.30$ to $5.40 ; \mathrm{p}<0.001)$.
\end{abstract}

Conclusion: Poor personal hygiene increases the risk of Leprosy.

Keywords: personal hygiene, Leprosy, meta-analysis

Correspondence:

Priscilla Jessica Pihaheys. Masters Program in Public Health. Universitas Sebelas Maret, Jl. Ir. Sutami 36A, Surakarta 57126, Central Java. Email: pihaheypriscilla@gmail.com. Mobile: o8114852336.

The $7^{\text {th }}$ International Conference on Public Health

Solo, Indonesia, November 18-19, $2020 \mid 98$

https://doi.org/10.26911/the7thicph.01.53 